\title{
Tempo de jejum na granja sobre o perfil hormonal e os parâmetros fisiológicos em suínos de abate pesados
}

\author{
Fasting time at farm on hormonal status and physiological parameters of heavy-weight slaughter pigs
}

\author{
Osmar Antonio Dalla Costa ${ }^{{ }^{*}}$ Jorge Vitor Ludke ${ }^{\mathrm{II}}$ Mateus José Rodrigues Paranhos da Costa ${ }^{\mathrm{III}}$ \\ Luigi Faucitano $^{\mathrm{IV}}$ Arlei ColdebellaI ${ }^{\mathrm{II}}$ Jalusa Deon Kich $^{\mathrm{II}}$ José Vicente Peloso $^{\mathrm{V}}$ Darlan Dalla Roza $^{\mathrm{VI}}$
}

\section{RESUMO}

O objetivo deste estudo foi avaliar o tempo de jejum na granja e a posição dos animais na carroceria do caminhão durante o transporte ao abatedouro sobre o status hormonal e fisiológico de suínos de abate pesados visando obter melhorias no manejo pré-abate e reduzir perdas na qualidade de carne. Foram utilizadas 64 fêmeas com peso médio de $133 \pm 11 \mathrm{~kg}$, oriundas de duas granjas de terminação. Os tempos de jejum avaliados foram nove, 12, 15 e 18h, enquanto que as posições consideradas na carroceria foram box (frente, meio e atrás), piso (inferior e superior) e lado (lateral direita e esquerda). Ao abate, foram medidos os níveis de glicose, lactato e CPK no sangue. A concentração de cortisol na saliva (CCS) foi medida nas granjas (24 horas antes e após embarque) e no abatedouro (logo após o descarregamento e antes do abate). A freqüência cardíaca foi monitorada durante todo o manejo pré-abate. Foi observado o efeito da interação entre TJG e o local de avaliação sobre a CCS e a freqüência cardíaca. A CCS e a freqüencia cardíaca aumentaram significativamente da granja ao desembarque no abatedouro em relação ao descanso pré-abate no abatedouro foi observada uma redução $(P<0,05)$ nos valores. A CCS variou em função do TJG e o local de avaliação da seguinte maneira: suínos com 18 horas de jejum apresentaram menor $(P<0,05)$ variação na CCS durante o transcorrer das diferentes etapas do manejo pré-abate do que suínos com TJG menores e, entre estes, os animais com TJG de nove horas apresentaram a maior $(P<0,05)$ variação. Antes do abate, os suínos com TJG de nove horas apresentaram o maior valor $(P<0,05)$ de CCS quando comparados aos outros TJG. Concluise que o TJG promove mudanças $(P<0,05)$ nos valores do cortisol na saliva e na freqüência cardíaca no manejo pré-abate, mas não afetam $(P>0,05)$ os níveis de glicose, lactato e CPK no abate dos suínos.

Palavras-chave: bem-estar animal, cortisol na saliva, creatina fosfo-quinase, freqüência cardíaca.

\section{ABSTRACT}

The aim of this study was to evaluate the effect of fasting time on the farm (TJG) and the position of the animals on truck compartment during transport to slaughterhouse in the hormonal and physiological status of heavy-weight swine in order to obtain future management improvements and to reduce meat quality downgrades. Sixty-four females obtained from two farms and averaging $133 \pm 11 \mathrm{~kg}$ body weight were used. Fasting time evaluated on farms were 9, 12, 15 and $18 \mathrm{~h}$ while the positions considered in the truck were Box (front, middle, and back), Deck (under and upper level) e Side (right and left). Swine blood concentration of glucose, lactate and $C P K$ were evaluated at slaughter. Cortisol concentration on saliva (CCS) was evaluated on the farm (24 hours before uploading and after loading) and at slaughterhouse (after downloading and before slaughter). Hearth frequency was continuously evaluated during pre-slaughter management. Interaction between TJG and moment of salivary cortisol sampling and heart rate data recording were observed. CCS and heart rate values increased from farm to truck downloading at slaughterhouse, while pre-slaughter resting reduced $(P<0.05)$ the values. The CCS values ranged in a gradient fashion in function of TJG and moment of salivary cortisol sampling in the following manner: pigs submitted to 18 hours of fasting showed smallest changes $(P<0.05)$ of CCS during the pre-

'Embrapa Suínos e Aves, CP 21, 89700-000, Concórdia, SC, Brasil. Programa de Pós-graduação em Zootecnia (Produção Animal), Faculdade de Ciências Agrárias e Veterinária (FCAV), Universidade Estadual Paulista (UNESP), Jaboticabal, SP, Brasil. E-mail: osmar@cnpsa.embrapa.br. *Autor para correspondência.

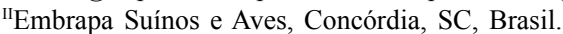

IIIDepartamento de Zootecnia, Grupo de Estudos e Pesquisas em Etologia e Ecologia Animal (ETCO), FCAV/UNESP, Jaboticabal, SP, Brasil.

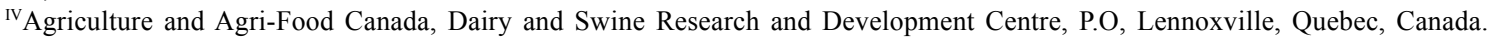

vadia S.A, Concórdia, SC, Brasil.

${ }^{\mathrm{V} T}$ Triel - HT Industria de Equipamentos Rodoviários Ltda, Erechim, RS, Brasil 
slaughter management when compared with CCS of pigs submitted to lower fasting times and, between those, the animals with 9 hours of fasting showed the greatest $(P<0.05)$ variations. Before slaughter swine submitted to 9 hours of fasting at farm presented the highest values $(P<0.05)$ of CCS when compared with the other fasting times evaluated. It is concluded that preslaughter management conditions affect $(P<0.05)$ the salivary cortisol levels and heart rate but the evaluated TJG had no effects $(P>0.05)$ on glucose, lactate and CPK levels at slaughter time.

Key words: animal welfare, creatine phospho-kinase, heart rate, salivary cortisol.

\section{INTRODUÇÃO}

Os fatores que desencadeiam o estresse dos suínos durante o manejo pré-abate causam de forma direta efeitos negativos sobre o bem-estar. Muitos relatos apresentados confirmam a necessidade de cuidados especiais no manejo pré-abate para manter os parâmetros fisiológicos em níveis normais porque estes são reflexo direto do bem-estar e têm, em última instância, relação com a qualidade da carne. O sistema de condução dos suínos (VAN DER WAL et al., 1999), o uso de choque elétrico (CHANNON et al., 2000), o tempo de jejum dos suínos na granja (LEHESKA et al., 2003; DALLACOSTA, 2005), os modelos de carroceria (DALLA COSTA, 2005) e o período de descanso no frigorífico(GEESINK et al., 2004; DALLACOSTA, 2005) foram descritos, demonstrando a influência significativa sobre a qualidade da carne dos suínos. A conjunção dos fatores estressantes durante o manejo pré-abate conduzem à elevada concentração de cortisol na saliva de suínos, que pode ser mensurada durante o transporte (GEVERINK et al., 1998a,b), mas os efeitos podem ser atenuados se, na retirada dos suínos das baias de descanso no frigorífico, for adotado o uso de tábua de manejo e a condução dos animais for realizada sem a utilização de choque elétrico com o auxilio de leves batidas sobre o dorso. Este procedimento pode atenuar a concentração do cortisol na saliva no abate $\mathrm{e}$ reduzir a freqüência de carcaças com problema de PSE (carne pálida, flácida e exudativa).

O tempo de jejum na granja deve ser aquele que não influencie negativamente a qualidade das carcaças dos suínos e o bem-estar dos animais durante o manejo pré-abate. Este tempo está vinculado à logística do frigorífico (condições do transporte, distância da granja, condições de alojamento nas baias de descanso e velocidade ou taxa de abate no frigorífico). Embora, sob o ponto de vista fisiológico, exista uma recomendação específica sobre o tempo de jejum ideal, tem sido observada uma grande variação em relação a este procedimento durante o manejo préabate. Todavia, GUARDIA et al. (1996) sugerem uma redução no jejum dos suínos (12 a 18h), enquanto MAGRAS et al. (2000) sugerem um jejum maior, entre 22 a $28 \mathrm{~h}$, com o objetivo de obter maior porcentagem de suínos com peso estomacal menor que $1,4 \mathrm{~kg}$. Já BEATTIE et al. (2002) observaram que jejum de $12 \mathrm{~h}$ antes do abate leva a uma economia de $1,5 \mathrm{~kg}$ de ração e, simultaneamente, não ocasiona perdas na qualidade de carcaça.

O bem-estar dos animais pode ser avaliado por meio dos índices de produtividade, do comportamento e mediante avaliação dos parâmetros fisiológicos, tais como cortisol, lactato, creatininafosfo-quinase e freqüência cardíaca. $\mathrm{O}$ manejo préabate pode promover situações estressantes aos animais, influenciando negativamente o seu bem-estar, o perfil hormonal, os níveis sangüíneos de cortisol, lactato, creatinina-fosfo-quinase (CPK) e sua freqüência cardíaca (PÉREZ et al., 2002a; DALLA COSTA et al., 2008; KÜCHENMEISTER et al., 2005).

O objetivo deste trabalho foi avaliar o efeito do tempo de jejum dos suínos na granja sobre os parâmetros fisiológicos no sangue (lactato, CPK e glicose), no abate dos suínos, sobre a concentração de cortisol na saliva e sobre a freqüência cardíaca durante as diferentes etapas do manejo pré-abate.

\section{MATERIAL E MÉTODOS}

No experimento foram utilizadas 64 (32 no inverno e 32 no verão) fêmeas oriundas de cruzamentos industriais com peso vivo médio de $134,5 \pm 9,7 \mathrm{~kg}$ no inverno e de $131,7 \pm 11,8 \mathrm{~kg}$ no verão e um período de alojamento médio de 144 dias, para concluir as fases de crescimento e terminação, oriundas de duas granjas em sistemas de terminação de suínos. Nas granjas avaliadas, foram escolhidas aleatoriamente quatro baias (repetições) por tempo de jejum dos suínos. Dos 10 animais em cada baia, foram escolhidos e identificados os dois mais uniformes (pesos semelhantes). No total, foram utilizadas 16 baias por granja para a realização do experimento. Para os tempos de jejum avaliados, a unidade experimental considerada foi constituída por dois animais dentro da baia.

Na granja, os animais foram alojados em baias coletivas com piso de concreto, com paredes de alvenaria rebocada, bebedouro do tipo concha (ecológico) e comedouro linear, paralelo ao corredor, com uma densidade média de 9,53 suínos por baia, e os animais tinham na baia uma área disponível de $1,10 \mathrm{~m}^{2}$ por suíno

No manejo pré-abate, os suínos foram submetidos a tempos de jejum na granja antes do 
embarque correspondendo a nove, 12,15 ou 18 horas. No desembarque dos suínos, no frigorífico, utilizou-se uma rampa móvel, sendo que os animais receberam um período de descanso médio no frigorífico de três horas. No deslocamento dos suínos (embarque e desembarque), não foram utilizados choques elétricos e os animais foram conduzidos com o auxílio de uma tábua de manejo.

O tempo médio para o embarque dos suínos na granja foi de 37 minutos. O transporte dos suínos foi realizado em um modelo de carroceria metálica dupla Triel-HT, com capacidade de transporte de 96 suínos, representando uma densidade média durante transporte de $0,45 \mathrm{~m}^{2}$ animal $^{-1}$ ou $294,33 \pm 18,50 \mathrm{~kg} \mathrm{~m}^{-2}$. As granjas estavam distantes do frigorífico, em média, a $34 \mathrm{~km}$ o que representou um tempo de trajeto de 53 minutos. Nesse modelo de carroceria, foram considerados os efeitos de piso (inferior e superior), do lado (direito e esquerdo) e posição (frente, meio e atrás).

Após o período de descanso, os animais foram encaminhados até o restrainer por meio de um corredor em forma de funil que permitia a passagem de apenas um suíno. O sistema de condução, caracterizado por uma esteira rolante, transportava os suínos imobilizados e sustentados pelos flancos até os eletrodos metálicos (localizados ao fim da esteira), que, em contato com o corpo dos animais, conduzia a descarga elétrica na região temporal (entre os olhos e a orelha) e peitoral. A insensibilização (ou eletro-narcose) era realizada automaticamente, aplicando alta voltagem (700V) e amperagem acima de 1,25A (Valhalla, Stork RMS bv, Lichtenvoorde, Holanda). Após a insensibilização, os animais eram imediatamente sangrados na posição horizontal e suspensos ao fim da mesa de sangria na nora, contínua da linha de abate.

No abate, no momento de realização da sangria dos animais com o auxílio de um béquer, foram coletadas amostras de sangue de oito suínos por tratamento em cada granja avaliada com um total de 64 amostras para a análise da creatina fosfoquinase - CPK (pelo método enzimático - Kit Wiener CK-NAC, Laboratório Wiener), Lactato Dehidrogenase (pelo método enzimático - Kit Rolsgreiner) e glicose (pelo método enzimático Kit Ebram-70-05-Laboratório Ebram). O monitoramento da freqüência cardíaca dos suínos foi realizado por meio da utilização do sistema Polar Team System $^{\mathrm{TM}}$. O aparelho receptor foi colocado ao redor do tórax, no lado esquerdo do suíno. As medidas foram registradas em intervalos de cinco segundos. A freqüência cardíaca dos suínos foi avaliada $24 \mathrm{~h}$ antes do manejo pré-abate na granja (FCGR), no período de zero a 12 horas e no dia do manejo do abate dos suínos, antes do embarque (FCEM) e do transporte (FCTR), e durante o período de descanso dos suínos no frigorífico (FCAB). Em função do grande número dos registros referentes à freqüência cardíaca, foi calculada a média das freqüências por suíno, em cada período de avaliação.

As amostras de saliva dos suínos foram coletadas com o auxílio de cotonetes grandes $(10 \mathrm{~cm})$, que eram introduzidos na boca dos suínos, deixando que mastigassem até que o algodão estivesse umedecido com saliva. Posteriormente, a saliva foi extraída do algodão mediante pressão e coletada em tubo Eppendorf, que foi armazenado a $-20^{\circ} \mathrm{C}$. A concentração de cortisol na saliva foi determinada por meio do kit Elisa Salimetrics. As amostras coletadas foram obtidas nos suínos avaliados em diferentes momentos do manejo pré-abate: a) na granja um dia antes do abate (CCGR) em cinco horários, às zero, três, seis, nove e 12 horas, dos quais se obteve a média desse período e b) no dia do abate em três momentos diferentes - após o embarque dentro da carroceria (CCEM), depois do desembarque na baia de descanso (CCDE) e uma hora antes de abate os animais (CCAB).

Os dados referentes à concentração de glicose (CG) e lactato desidrogenase (CL) transformados para o logaritmo natural (Ln) e os dados referentes a CPK foram analisados pelo procedimento GLM (SAS, 2001), utilizando-se do seguinte modelo: $\mathrm{Y}_{\mathrm{ijklmn}}=\mu+\mathrm{BL}_{\mathrm{i}}+\mathrm{TJG}_{\mathrm{j}}+(\mathrm{BL} \times \mathrm{TJG})_{\mathrm{ij}}+\mathrm{PBO}_{\mathrm{k}}+\mathrm{PPI}_{1}+$ $\mathrm{PLA}_{\mathrm{m}}+\mathrm{e}_{\mathrm{ijklmn}}, \mathrm{Y}_{\mathrm{ijklmn}}=$ concentração de glicose $(\mathrm{CG})$, lactato $(\mathrm{CL})$ e CPK no sangue dos suínos; $\mu=$ média geral; $\mathrm{BL}_{\mathrm{i}}=$ bloco (estação do ano, $\mathrm{i}=1$ inverno e 2 verão); $\mathrm{TJG}_{\mathrm{j}}=$ tempo de jejum dos suínos na granja $\mathrm{j}=$ 1 (jejum de nove horas), 2 (jejum de $12 \mathrm{~h}$ ); 3 (jejum de $15 \mathrm{~h})$ e 4 (jejum de $18 \mathrm{~h}$ ); $\mathrm{PBO}_{\mathrm{k}}=$ posição do animal na arroceria, $\mathrm{k}=1$ (frente), 2 (meio) e 3 (atrás); $\mathrm{PPI}_{1}=$ piso da carroceria, $1=1$ (inferior) e 2 (superior); $\mathrm{PLA}_{\mathrm{m}}=$ lado da carroceria, $\mathrm{m}=1$ (direito) e 2 (esquerdo); $(\mathrm{BL} \times \mathrm{TJG})_{\mathrm{ij}}$ $=$ interação entre bloco e período de descanso dos suínos no frigorífico antes do abate; $\mathrm{e}_{\mathrm{ijklmn}}=$ erro aleatório associado à cada observação.

Os dados de concentração de cortisol transformados para o logaritmo natural (Ln) e os dados referentes à freqüência cardíaca foram analisados utilizando o seguinte modelo estatístico: $\mathrm{Y}_{\mathrm{ijkl}}=\mu+\mathrm{BL}_{\mathrm{i}}$ $+\mathrm{TJG}_{\mathrm{j}}+\left(\mathrm{BL}_{\mathrm{i}} \times \mathrm{TJG}_{\mathrm{j}}\right)+\varepsilon_{\mathrm{ijk}}+\mathrm{LO}_{1}+\left(\mathrm{LO}_{1} \times \mathrm{BL}_{\mathrm{i}}\right)+\left(\mathrm{LO}_{1} \times\right.$ $\left.\mathrm{TJG}_{\mathrm{j}}\right)+\left(\mathrm{LO}_{1} \times \mathrm{BL}_{\mathrm{i}} \times \mathrm{TJG}_{\mathrm{j}}\right)+\mathrm{e}_{\mathrm{ijkl}}$, sendo: $\mathrm{Y}_{\mathrm{ijkl}}=$ concentração de cortisol na saliva e freqüência cardíaca dos suínos; $\mu=$ média geral; $\mathrm{BL}_{\mathrm{i}}=$ bloco (estação do ano, $\mathrm{i}=1$ inverno e 2 verão); $\mathrm{TJG}_{\mathrm{j}}^{\mathrm{i}}=$ tempo de jejum na granja, $\mathrm{j}=1$ (jejum de $9 \mathrm{~h}$ ), 2 (jejum de $12 \mathrm{~h}$ ); 3 (jejum de $15 \mathrm{~h})$ e 4 (jejum de $18 \mathrm{~h})$; $(\mathrm{BL} \times \mathrm{TJG})_{\mathrm{ij}}=$ interação entre bloco e período de descanso dos suínos no frigorífico; $\varepsilon_{\mathrm{ijk}}=$ erro aleatório correspondente à parcela, suposto homocedástico, independente e normalmente 
distribuído; $\mathrm{LO}_{1}=$ local da coleta da saliva e da freqüência cardíaca dos suínos, $1=1$ (na granja $24 \mathrm{~h}$ antes do embarque dos suínos CCGR, FCGR); 2 (freqüência cardíaca dos suínos antes do embarque FCEM e concentração do cortisol após o embarque dos suínos no caminhão CCEM); 3 (freqüência cardíaca dos suínos no transporte FCTR e cortisol após a desembarque no frigorífico CCDE); 4 (concentração do cortisol $\mathrm{CCAB}$ e a freqüência cardíaca $\mathrm{FCAB}$ antes do abate dos suínos, na baia de descanso no frigorífico); $(\mathrm{LO} \times \mathrm{BL})_{\mathrm{li}}=$ interação entre local da coleta da saliva dos suínos e bloco; $(\mathrm{LO} \times \mathrm{TJG})_{\mathrm{lj}}=$ interação entre local da coleta da saliva dos suínos e período de descanso dos suínos no frigorífico; $(\mathrm{LO} \times \mathrm{BL} \times \mathrm{TJG})_{\mathrm{lij}}=$ interação entre local da coleta da saliva dos suínos e bloco e período de descanso dos suínos no frigorífico; $\mathrm{e}_{\mathrm{ijkl}}=$ erro aleatório correspondente à subparcela, suposto homocedástico, independente e normalmente distribuído.

\section{RESULTADOS E DISCUSSÃO}

O tempo de jejum dos suínos na granja não teve influência sobre o nível da glicose $(\mathrm{P}=0,37)$ e nem sobre as concentrações de lactato $(\mathrm{P}=0,22)$ e $\mathrm{CPK}(\mathrm{P}=0,21)$ no sangue dos suínos na hora do abate (Tabela 1). Os resultados obtidos no presente estudo validam os resultados encontrados por LEHESKA et al. (2003) que não encontraram efeito do jejum sobre a diferença da concentração de glicose no sangue antes e depois do jejum. Os valores apresentados diferem dos resultados obtidos por WARRISS \& BROWN (1983), que verificaram um efeito significativo do jejum sobre a concentração da glicose no sangue, em suínos que estiveram em jejum de nove, 18 e $24 \mathrm{~h}$ apresentaram menor concentração de glicose, em comparação aos animais que estavam em jejum de zero, três, nove e 18 horas.

No presente estudo não foi encontrado efeito do tempo de jejum no nível da glicose e nas concentrações de lactato e CPK no sangue dos suínos. Estes resultados podem ser atribuídos ao manejo em que os suínos foram submetidos, à ausência do uso do choque elétrico para a condução dos animais por equipe qualificada e ao uso de tábua de manejo (manejo com baixo estresse), associado à duração e à densidade de transporte durante o manejo pré-abate.

A localização do box dentro da carroceria (frente, meio e atrás) não influenciou o nível da glicose $(\mathrm{P}=0,80)$, do lactato $(\mathrm{P}=0,62)$ e do $\operatorname{CPK}(\mathrm{P}=0,23)$ no sangue dos suínos ao abate. Suínos transportados no piso superior da carroceria do caminhão apresentaram valores do nível de glicose do sangue na hora do abate menores $(\mathrm{P}=0,04)$ em relação aos transportados no piso inferior da carroceria do caminhão. Isso pode estar relacionado ao fato de os suínos no piso superior estarem mais expostos ao ambiente externo, com uma sensação térmica menor do que aqueles embarcados no piso inferior, em especial quando há o deslocamento do caminhão. Nesta circunstância se apresenta uma diferença de $4,6 \%$ na concentração de glicose, que deve ser devida ao gasto adicional de energia prontamente disponível para manter a homeostase na temperatura

Tabela 1 - Níveis de glicose $\left(m g \mathrm{dL}^{-1}\right)$, CPK (UI) e lactato $\left(\mathrm{mg} \mathrm{dL}^{-1}\right)$ ao abate em função do tempo de jejum dos suínos na granja antes do embarque dos suínos e da posição dos suínos na carroceria.

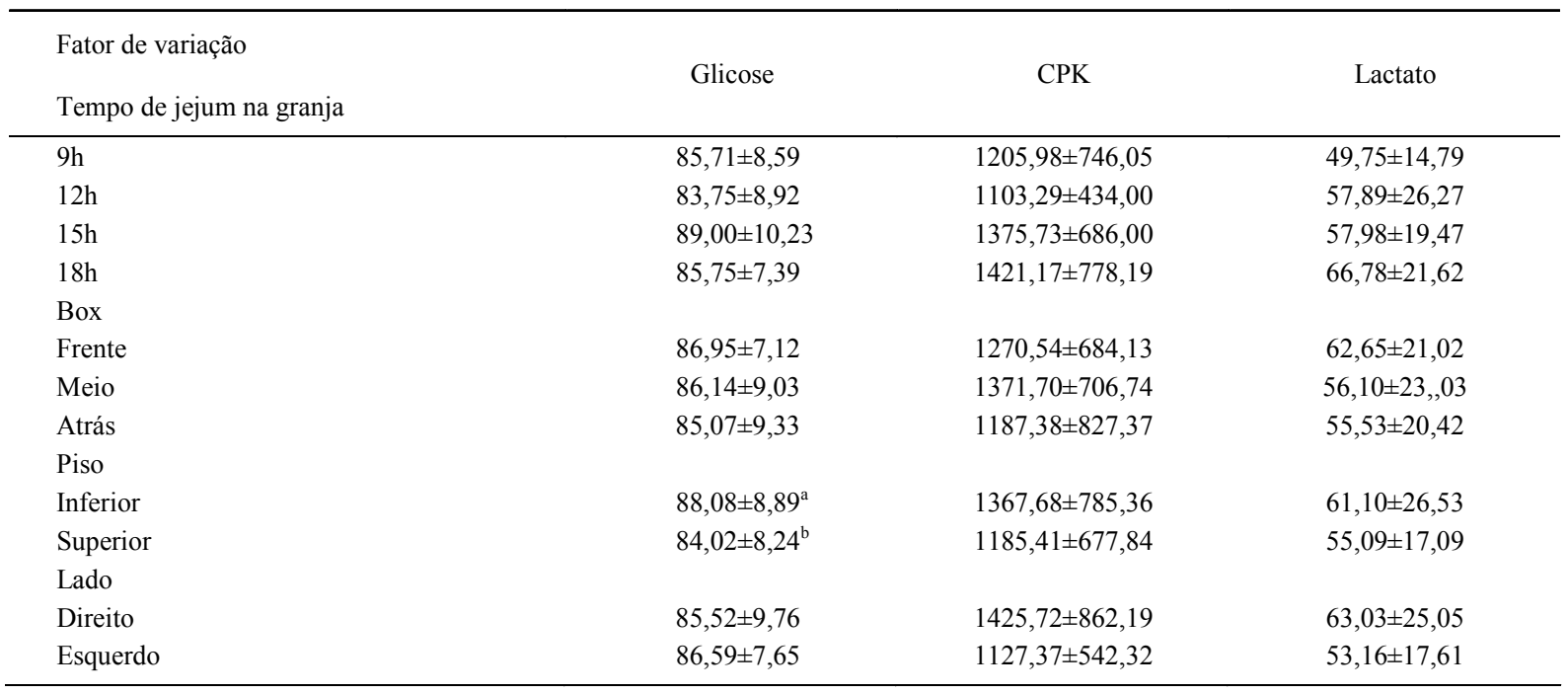

Na coluna, para cada grupo de fatores de variação, as médias seguidas de letras minúsculas distintas diferem pelo teste $\mathrm{T}$ (P<0,05). 
corporal. Contudo, o piso da carroceria não influenciou o nível de lactato $(\mathrm{P}=0,51)$ e o $\mathrm{CPK}(\mathrm{P}=0,19)$ no sangue dos suínos. $\mathrm{O}$ lado da carroceria não influenciou o nível da glicose $(\mathrm{P}=0,58)$, o lactato $(\mathrm{P}=0,12)$ e o $\mathrm{CPK}(\mathrm{P}=0,15)$ no sangue dos suínos. Os resultados obtidos no presente estudo estão de acordo com aqueles obtidos por DALLA COSTA et al. (2008), que não observaram efeito do período de descanso e da posição do box da carroceria sobre a concentração de glicose, CPK e lactato no sangue dos suínos abatidos.

A concentração do cortisol na saliva (CCS) dos suínos $24 \mathrm{~h}$ antes do embarque, no embarque, no desembarque e antes do abate dos suínos na baia de descanso em função da interação tempo de jejum dos suínos e locais de avaliação estão representados na tabela 2. Observou-se efeito $(\mathrm{P}=0,003)$ da interação tempo de jejum dos suínos e locais da avaliação. Não foi observado efeito $(\mathrm{P}>0,05)$ do local da avaliação do cortisol nos suínos submetidos a jejum de $18 \mathrm{~h}$. Contudo, verificou-se um efeito $(\mathrm{P}<0,05)$ do local da avaliação do cortisol dos suínos submetidos a jejum de nove, 12 e 15 horas na granja. Suínos que foram submetidos a jejum de $18 \mathrm{~h}$ na granja apresentaram maiores valores de CCS na granja e no embarque, em relação aos que receberam jejum de nove , 12 e 15 horas. No entanto, isso não foi observado no desembarque e nem antes do abate, pois nessa etapa do manejo verificou-se uma redução na CCS dos animais que receberam jejum de $18 \mathrm{~h}$. Suínos que receberam jejum de nove, 12 e 15 horas apresentaram um incremento na CCS no desembarque e antes do abate. $\mathrm{O}$ tempo de jejum dos suínos na granja influenciou $(\mathrm{P}=0,02)$ a $C C S$, pois suínos que receberam jejum de nove horas de jejum na granja apresentaram maiores valores do cortisol, contudo, não diferiram $(\mathrm{P}>0,05)$ daqueles que receberam $18 \mathrm{~h}$ de jejum na granja e os suínos que receberam 12 e 15 horas de jejum na granja apresentaram menores valores do cortisol, não diferindo $(\mathrm{P}>0,05)$ entre si.

Independente do tempo de jejum dos suínos na granja, a CCS dos suínos aumenta da granja ao desembarque dos animais no frigorífico. Com o descanso no frigorífico, observou-se uma redução nos valores do cortisol antes do abate. O cortisol no desembarque foi maior $(\mathrm{P}<0,05)$ em relação aos demais locais avaliados e na granja e após embarque foram observados os menores valores, os quais não diferiram $(\mathrm{P}>0,05)$ entre si. Com o deslocamento dos suínos da baia da granja até o desembarque no frigorífico, foi observado um incremento de 2,67 vezes na CCS dos suínos. Este valor está relacionado ao estresses da retirada dos suínos da baia, do deslocamento e do embarque no caminhão, condições de transporte e desembarque no frigorífico. Após um período de descanso de três horas a CCS foi reduzida em $27,6 \%$ quando foi feito desembarque, porém, não retornou às concentrações da granja, podendo indicar que este período de descanso tenha que ser ampliado. Os resultados obtidos no presente estudo estão de acordo com GEVERINK et al. (1998a,b), os quais verificaram que o manejo pré-abate dos suínos contribui para o incremento na CCS dos animais e dos encontrados por PÉREZ et al. (2002b), os quais observaram que suínos transportados por 15 minutos e abatidos após o transporte apresentaram maiores valores de cortisol no sangue em relação aos animais que foram transportados por três horas. Contudo, os resultados diferem dos encontrados por GEERS et al. (1994), que não verificaram um aumento no cortisol dos suínos portadores dos genes halotano nn após o transporte. Dentro do manejo pré-abate o tempo de jejum não influenciou $(\mathrm{P}>0,05)$ a concentração do cortisol no sangue dos suínos (GEERS et al., 1994; BROWN et al., 1999; DALLACOSTA et al. (2007).

No presente estudo, observou-se um aumento do cortisol da saliva durante o período do manejo pré-abate (da granja ao abate). Esses resultados estão de acordo com os obtidos por JONG et al. (2000), que também verificaram um aumento na concentração do cortisol da saliva dos suínos criados em ambientes pobres (baia com os suínos), na granja após o transporte e na baia de descanso em relação ao período

Tabela 2 - Concentração do cortisol da saliva ( $\mu \mathrm{g} / \mathrm{dL})$ dos suínos em função das interações entre tempo de jejum dos suínos e local da colłta.

\begin{tabular}{lccccc}
\hline & & & & \\
Local/ & \multicolumn{1}{c}{12} & & 15 & \\
Média \\
\hline Granja & $0,224 \pm 0,166^{\mathrm{aC}}$ & $0,252 \pm 0,126^{\mathrm{aB}}$ & $0,260 \pm 0,166^{\mathrm{aB}}$ & $0,333 \pm 0,267^{\mathrm{aA}}$ & $0,267 \pm 0,188^{\mathrm{C}}$ \\
Embarque & $0,288 \pm 0,238^{\mathrm{bC}}$ & $0,210 \pm 0,137^{\mathrm{bB}}$ & $0,274 \pm 0,293^{\mathrm{bB}}$ & $0,503 \pm 0,493^{\mathrm{aA}}$ & $0,319 \pm 0,330^{\mathrm{C}}$ \\
Desembarque & $1,039 \pm 0,796^{\mathrm{aA}}$ & $0,682 \pm 0,537^{\mathrm{bA}}$ & $0,592 \pm 0,737^{\mathrm{bA}}$ & $0,542 \pm 0,393^{\mathrm{bA}}$ & $0,714 \pm 0,654^{\mathrm{A}}$ \\
Antes do abate & $0,717 \pm 0,390^{\mathrm{aB}}$ & $0,436 \pm 0,503^{\mathrm{bB}}$ & $0,442 \pm 0,395^{\mathrm{bAB}}$ & $0,444 \pm 0,455^{\mathrm{bA}}$ & $0,510 \pm 0,445^{\mathrm{B}}$ \\
Média & $0,567 \pm 0,515^{\mathrm{a}}$ & $0,395 \pm 0,415^{\mathrm{b}}$ & $0,392 \pm 0,461^{\mathrm{b}}$ & $0,456 \pm 0,409^{\mathrm{ab}}$ & $0,452 \pm 0,469$ \\
\hline
\end{tabular}

Médias seguidas de letras minúsculas na mesma linha distintas diferem pelo teste $\mathrm{T}(\mathrm{P}<0,05)$.

Médias seguidas de letras maiúsculas na mesma coluna distintas diferem pelo teste $\mathrm{T}(\mathrm{P}<0,05)$.

Ciência Rural, v.38, n.8, nov, 2008. 
anterior ao manejo pré-abate. Porém, esses pesquisadores não observaram um aumento no cortisol durante o manejo pré-abate em suínos criados em ambientes melhorados, com a disponibilização de objetos dentro da baia (bolas, correntes). DALLA COSTA et al. (2007) também observaram um aumento da concentração da saliva dos suínos no período que compreende a retirada dos animais das baias na granja ao abate dos suínos após o descanso no abatedouro. Os resultados de CCS demonstram que os valores não se alteraram significativamente quando comparados os locais de coleta: antes do manejo pré-abate na granja e em cima do caminhão com animais recém-embarcados. O tempo decorrido entre a retirada dos animais das baias e a coleta em cima do caminhão foi, em média, de apenas 10 minutos e isso demonstra que com este intervalo não há alteração significativa na saliva. A alteração da concentração nos níveis de cortisol é mais rapidamente mensurável no sangue, após na saliva e, mais tardiamente, por último, na urina. As coletas realizadas após o desembarque ocorreram em um intervalo de 90 minutos, entre a retirada dos animais das baias nas granjas e o alojamento nas baias de descanso no abatedouro. Entre um e outro evento, ocorreu o transporte que se caracteriza como ser o estresse mais intenso. Quando avaliado em relação ao nível de cortisol apresentado nas granjas, verifica-se que a CCS dos animais ao desembarque tem um gradiente em função do tempo de jejum na granja, ou seja, os aumentos verificados no nível de cortisol foram de $63,128,171$ e $363 \%$, respectivamente, para os tempos de jejum de 18, 15, 12 e nove horas. Antes do abate este mesmo gradiente ainda se repete com valores de cortisol superiores em 37, 70, 73 e 120\%, respectivamente. A menor variação verificada nos níveis de cortisol nos animais submetidos ao tempo de jejum de $18 \mathrm{~h}$ entre os diferentes locais de coleta deve estar condicionada ao fato de que o jejum prolongado por si só já se caracteriza como potente agente estressor. Após o embarque, o nível de cortisol nos suínos submetidos ao jejum de $18 \mathrm{~h}$ era $95 \%$ superior à média apresentada pelos animais que foram submetidos aos tempos de jejum menores. Acredita-se que ocorra uma continuada e sustentada secreção de cortisol quando ocorre o jejum de $18 \mathrm{~h}$, porém, as respostas a agentes estressores adicionais, como transporte até o abatedouro, serão percebidas com menor amplitude, porque existe um limite fisiológico natural. O contrário ocorre com animais submetidos ao jejum de nove horas, pois apresentam uma concentração de cortisol ao desembarque e antes do abate que são, respectivamente, 72 e $63 \%$ superiores aos animais submetidos a tempos de jejum maiores. Considerando a concentração de cortisol na saliva para escolher o melhor tempo de jejum na granja, deve ser observado um conjunto de fatores: 1) o nível de cortisol deve ser o mais baixo possível o máximo de tempo durante todas as etapas do manejo pré-abate, 2) os picos de concentração de cortisol apresentados nas fases mais críticas do manejo pré-abate devem ser de baixa amplitude e 3) o valor final de cortisol na saliva antes do abate deve ser o mais próximo possível do valor normal apresentado pelos animais na granja antes do início do manejo pré-abate. Nestas circunstâncias, para reduzir a CCS antes do abate, é provável que seja necessário um maior tempo de descanso no abatedouro para os suínos que foram submetidos ao jejum de nove horas. Para um descanso total de três horas no abatedouro antes do abate, o melhor tempo de jejum a escolher se situa entre 12 e 15 horas. Isso caracteriza um período total de 16 a 20 horas entre o início do jejum e o abate dos animais.

O tempo de jejum na granja não influenciou $(\mathrm{P}=0,38)$ a freqüência cardíaca dos suínos durante o manejo pré-abate dos suínos. Entretanto, verificou-se um efeito $(\mathrm{P}<0,01)$ do local da avaliação da freqüência cardíaca dos suínos. Independente do tempo de jejum na granja, no transporte, foram observados maiores valores da freqüência cardíaca dos suínos, diferindo $(\mathrm{P}<0,05)$ dos demais locais de avaliação e, antes do embarque dos suínos na granja, foram observados os menores valores de freqüência cardíaca. Mesmo tendo observado um efeito do local da avaliação, biologicamente esses valores podem ser considerados como adequados, pois, no presente estudo, foram utilizadas fêmeas suínas pesadas, o que pode ter contribuído para um incremento desta freqüência cardíaca. Os resultados obtidos no presente estudo são validados por VILLÉ et al. (1993), GEERS et al.(1994), GEVERINK et al. (1998b) e DALLACOSTA et al. (2008), que também observaram um aumento na freqüência cardíaca dos suínos após o seu transporte.

Mesmo tendo encontrado efeito do tempo de jejum na granja e do local de avaliação sobre o nível de cortisol, pode-se considerar que estes valores estão dentro do padrão fisiológico da categoria de animais avaliados e os procedimentos do manejo pré-abate deste estudo não promoverão detrimento ao bem-estar dos suínos.

\section{CONCLUSÕES}

O tempo de jejum durante o manejo pré-abate não influenciou as concentrações de glicose, lactato desidrogenase e de creatina fosfoquinase (CPK) avaliadas no sangue ao abate dos animais. A concentração do cortisol da saliva dos suínos teve 
aumento da granja até o desembarque dos suínos no frigorífico. O período de descanso nas baias do abatedouro proporcionou uma redução na sua concentração, entretanto, os valores ainda foram superiores aos valores médios obtidos nas granjas $24 \mathrm{~h}$ antes do inicio do jejum. Os valores médios da freqüência cardíaca durante o manejo pré-abate dos suínos estavam dentro dos padrões fisiológicos para o grupo genético e o peso corporal. A freqüência cardíaca dos suínos foi maior durante o transporte em relação às demais fases do manejo pré-abate.

\section{REFERÊNCIAS}

BEATTIE, V.E. et al. The effect of food deprivation prior to slaughter on performance, behaviour and meat quality. Meat Science, Kidlington, v.62, p.413-418, 2002.

BROWN, S.N. et al. Relationship between food deprivation before transport and aggression in pigs held in lairage before slaughter. Veterinary Record, London, v.145, p.630-634, 1999.

CHANNON, H.A. et al. Halothane genotype, pre-slaughter handling and stunning method all influence pork quality. Meat Science, Kidlington, v.56, p.291-299, 2000.

DALLA COSTA, O.A. Efeito do manejo pré-abate no bemestar e na qualidade de carne de suínos. 2005. Tese (Doutorado em Zootecnia) - Faculdade de Ciências Agrárias e Veterinária - Universidade Estadual Paulista, Jaboticabal.

DALLA COSTA, O.A. et al. Efeito do manejo pré-abate sobre o perfil hormonal e parâmetros fisiológicos em suínos de abate pesados. Ciência Rural, Santa Maria, no prelo, 2008.

GEERS, R. et al. Transport of pigs different with respect to the halothane gene: stress assessment. Journal of Animal Science, Champaign, v.72, p.2552-2558, 1994.

GEESINK, G.H. et al. Short-term feeding strategies and pork quality. Meat Science, Kidlington, v.67, p.1-6, 2004.

GEVERINK, N.A. et al. Effects of regular moving and handling on the behavioral and physiological responses of pigs to preslaughter treatment and consequences for subsequent meat quality. Journal Animal Science, Champaign, v.76, p.20802085, 1998a.

GEVERINK, N.A. et al. Responses of slaughter pigs to transport and lairage sounds. Physiology \& Behavior, Amsterdam, v.63, p.667-673, 1998 b.

GUARDIA, M.D. et al. Mortality rates during transport and lairage in pigs for slaughter. Meat Foccus International, Wallingford, v.4, p.362-366, 1996.

JONG, I.C. et al. Effects of rearing conditions on behavioural and physiological responses of pigs to pre-slaughter handling and mixing at transport. Canadian Journal of Animal Science, Ottawa, v.80, p.451-458, 2000

KÜCHENMEISTER, U. et al. Pre-slaughter handling of pigs and the effect on heart rate, meat quality, including tenderness, and sarcoplasmic reticulum $\mathrm{Ca}^{2+}$ transport. Meat Science, Kidlington, v.71, p.690-695, 2005.

LEHESKA, J.M. et al. Effects of fasting and transportation development and extent of postmortem metabolism. Journal Animal Science, Champaign, v.81, p.3194-3202, 2003.

MAGRAS, C. et al. Quelles durées de mise à jeun des porcs charcutiers pour um optimun de qualité dês carcasses? Détermination à partir dún étude terrain. Journées Recherche Porcine em France, Paris, v.32, p.351-356, 2000.

PÉREZ, M.P. et al. Influence of lairage time on some welfare and meat quality parameters in pigs. Veterinary Record, London, v.33, p.239-250, 2002a.

PÉREZ, M.P. et al. Effect of transport time on welfare and meat quality parameters in pigs. Meat Science, Kidlington, v.61, p.425-433, 2002b.

SAS INSTITUTE. System for Microsoft Windows: release 8.2. Cary, 2001. 1 CD-ROM.

VAN DER WAL, P.G. et al. The effect of stress, applied immediately before stunning, on pork quality. Meat Science, Kidlington, v.53, p.101-106, 1999.

VILLÉ, H. et al. Electrocardiogram parameters of piglets during housing, handling and transport. Animal Production, Edindurg, v.56, p.211-216, 1993.

WARRISS, P.D.; BROWN, S.N. The influence of preslaughter fasting on carcass and liver yield in pigs. Livestock Production Science, Amsterdam, v.10, p.273-282, 1983. 